\title{
High-resolution ice-core stable-isotopic records from Antarctica: towards interannual climate reconstruction
}

\author{
David P. SCHNEIDER, ${ }^{1}$ Eric J. STEIG, ${ }^{1}$ Tas VAN OMMEN ${ }^{2}$ \\ ${ }^{1}$ Department of Earth and Space Sciences, University of Washington, Seattle, WA 98195-1310, USA \\ E-mail: schneidd@u.washington.edu \\ ${ }^{2}$ Department of the Environment and Heritage, Australian Antarctic Division and Antarctic Climate and Ecosystems CRC, \\ Hobart, Tasmania 7001, Australia
}

\begin{abstract}
Ice-core records are a key resource for reconstructing Antarctic climate. However, a number of physical processes preclude the simple interpretation of ice-core properties such as oxygen isotopic ratios in terms of climate variables like temperature or sea-level pressure. We show that welldated, sub-annually resolved stable-isotopic records from the United States International TransAntarctic Scientific Expedition (US-ITASE) traverses and other sources have a high correlation with local seasonal temperature variation. However, this temporal relationship cannot be simply extended to quantitative interannual resolution reconstructions of site temperature. We suggest that a consistent and important target for ice-core calibrations is a composite of annual mean temperature records from Antarctic weather stations, which covaries strongly with the dominant mode (from principal component analysis) of temperature variability in the Antarctic. Significant correlations with this temperature index are found with individual ice-core records, with a composite of the ice cores, and through a multiple linear regression model with the ice cores as predictors. These results imply that isotopic signals, like the instrumental temperature mode itself, have a strong response to large-scale atmospheric circulation variability, which in the Antarctic region is dominated by the Southern Annular Mode.
\end{abstract}

\section{INTRODUCTION}

Globally averaged temperatures have risen markedly in the last 100 years, and early-21st-century climate is likely to be outside the bounds of natural climate variability over the last millennium (e.g. Houghton and others, 2001; Karl and Trenberth, 2003). Relatively little can be said with any certainty, in this context, about recent climate change in Antarctica, because the instrumental record is too short and geographically sparse. Proxy climate information from ice cores in Antarctica provides a longer and more spatially detailed history of climate change than is available from direct observations.

Isotopic ratios of oxygen and hydrogen in polar ice cores have been used extensively as temperature proxies and, when calibrated with instrumental data, are often viewed as a paleothermometer. However, many physical factors in addition to temperature determine the isotopic content of accumulated snow and ice, making extraction of proxy climate information from ice cores a difficult task in practice. Classically, a Rayleigh distillation model, with control parameters of the initial isotopic mass of the water vapor in an air parcel and the fraction of vapor mass that remains when precipitation forms at the deposition site, is used to explain highly correlated spatial and seasonal isotope-temperature relationships (e.g. Dansgaard, 1964). More sophisticated general circulation models suggest several other controlling factors, which include the seasonal timing of precipitation, the source region conditions and the mixing of air parcels (e.g. Cole and others, 1999; Noone and Simmonds 2002a, b; Werner and Heimann, 2002).

Recent studies focused on Antarctica have found a disparity among different ice-core sites in both the spatial and temporal isotope-temperature slopes, and potentially large imprints of source region conditions on the isotopic signal (Van Ommen and Morgan, 1997; Van Lipzig and others, 2002; Masson-Delmotte and others, 2003; Vaughan and others, 2003). To date, few interannual calibrations of ice cores have been attempted (Masson-Delmotte and others, 2003), although interpretations of stable isotopes as proxies of site temperature are frequently offered (e.g. Mosley-Thompson and others, 1990; Stenni and others, 2002; Vaughan and others, 2003; Mayewski and others, 2004), usually on lower-resolution (decades to centuries) timescales.

Large-scale features of the atmospheric circulation can strongly affect the isotopic ratios of precipitation through modulation of the condensation history of air masses reaching Antarctica, the location of the moisture source region and the isotopic signature of the source water. The effect that circulation anomalies have on local temperature may only explain a small part of the local isotopic response (Noone and Simmonds, 2002a, b; Masson-Delmotte and others, 2003). Thus, a single isotopic record may not be well related to local temperature changes, but may more strongly reflect large-scale circulation features. Additionally, each location will be subject to local noise, caused by variations in precipitation timing, accumulation rate, post-depositional alteration and local circulation regimes.

Here, we consider the sensitivity of stable isotopes to seasonal and interannual variations in local temperature, and, in keeping with the modeling studies discussed above, also use multiple records to reconstruct a spatially averaged interannual temperature history representative of the Antarctic region as a whole. While seasonal correlations are very strong, a single temporal isotope-temperature relationship that is common to all sites cannot be well defined. Focusing on reconstructing the regional temperature record, as inferred from Antarctic weather stations, we find that standard linear techniques (multiple linear regression and 

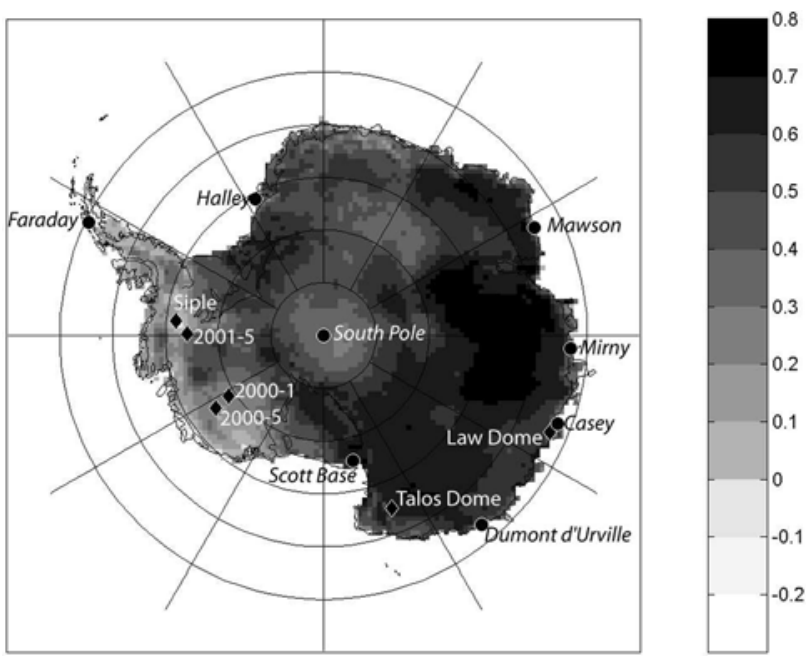

Fig. 1. Map of Antarctica, with ice-core sites indicated by diamonds, and stations with surface air-temperature observations, which are used to construct A8, indicated by large dots. Background shading is the correlation coefficient of A8 with annual mean satellite-derived surface temperature anomalies at each gridbox from 1982 to 1999.

compositing) applied to multiple ice-core time series yield consistent and promising results. The signal common to the instrumental and ice-core records reflects the dominance of the Southern Annular Mode (SAM) on both isotopic and temperature variations over the continent (Noone and Simmonds, 2002a; Schneider and others, 2004).

\section{DATA}

We use three ice cores from the United States International Trans-Antarctic Scientific Expedition (US-ITASE) (cores 2000-1, 2000-5 and 2001-5) for which high-resolution (sub-annual) isotopic measurements and precise dating have been completed (Dixon and others, 2004; Steig and others, 2005). More analyses on the US-ITASE data, which will include more than two dozen ice-core profiles, are ongoing. We also use isotopic records that are at least annually resolved from three previous drilling projects: Siple Station (Mosley-Thompson and others, 1990), Talos Dome (Stenni and others, 2002) and Law Dome. The Law Dome record consists of Law Dome DSS97, a single core available at quasi-monthly resolution to 1996, and Law Dome 2000, a stack of one to three cores from the same site, including
DSS97, available at annual resolution to 1999. The dating of the Law Dome cores is discussed by Palmer and others (2001) and Van Ommen and others (2004). A map depicting the locations of these cores is displayed in Figure 1, and site characteristics are listed in Table 1.

Timescales for the US-ITASE cores are based on wellresolved seasonal cycles in ice-core chemistry, with validation from volcanic horizons of known age (Dixon and others, 2004). On the basis of several validation tests, Steig and others (2005) estimate an accuracy of $< \pm 1$ year and a precision of \pm 2 months for these cores. We make minor adjustments to the timescales described by Dixon and others (2004), since a 'core chemistry year', defined primarily by annual non-sea-salt sulfate peaks, will not always line up precisely in depth with an 'isotopic year', defined as the interval between summer isotopic peaks. The isotopic peaks are assigned to 1 January. This avoids aliasing that may arise from the difference in timing ( \pm 1 month; Steig and others, 2005) of the isotopic and sulfate peaks, biasing the isotope record towards a particular season. Adjustment of the timescale is practical only in the highest-resolution portions of the isotope records where annual cycles are clearly defined. This is the case for the portions of the ice-core records discussed here. It should be noted that the number of years in the two timescales is not different; only subannual adjustments are made. Isotopic peaks have also been assigned to 1 January in the Law Dome records.

To facilitate calibration against meteorological data, the ice-core timescales are linearly interpolated to monthly resolution between summer markers for the US-ITASE and Law Dome cores. This assumes a constant accumulation rate throughout the year. While this assumption is not strictly valid, these sites have relatively high annual accumulation rates (Table 1), and, as shown below, the isotopic cycles are clearly defined and have high $\left(r^{2} \sim 0.96\right)$, significant correlations with seasonal variations in temperature. Specific significance levels (when above 90\%) cited henceforth are based on a two-tailed $t$ test while reducing the number of degrees of freedom to account for autocorrelation in the data (see Bretherton and others, 1999, section 5). Throughout this paper, we use the shorthand ' $\delta$ ' to refer interchangeably to oxygen and deuterium isotope ratios, unless distinction is necessary. $\delta^{18} \mathrm{O}$ and $\delta \mathrm{D}$ in units of per mil (\%) are reported as $=\left(R / R_{\text {VSMOW }}-1\right)$, where $R$ is the ratio of ${ }^{18} \mathrm{O} /{ }^{16} \mathrm{O}$ or $\mathrm{D} / \mathrm{H}$ and VSMOW is Vienna Standard Mean Ocean Water. All data are normalized to the VSMOW/SLAP (Standard Light Antarctic Precipitation) standards from the International Atomic Energy Agency.

Table 1. Ice-core records investigated in this study

\begin{tabular}{|c|c|c|c|c|c|c|c|}
\hline \multirow[t]{2}{*}{ Core name } & \multirow[t]{2}{*}{ Location } & \multirow[t]{2}{*}{ Elevation } & \multirow{2}{*}{$\begin{array}{l}\text { Mean annual } \\
\text { temperature } \\
\text { from satellite } \\
{ }^{\circ} \mathrm{C}\end{array}$} & \multirow[t]{2}{*}{$\begin{array}{l}\text { Period of } \\
\text { record } \\
\text { (this study) }\end{array}$} & \multirow[t]{2}{*}{$\begin{array}{l}\text { Isotope } \\
\text { analyzed }\end{array}$} & \multirow{2}{*}{$\begin{array}{c}\text { Mean } \delta \\
1961-90 \\
\text { \%о }\end{array}$} & \multirow{2}{*}{$\begin{array}{c}\text { Accumulation } \\
\text { rate, 1982-99 } \\
\mathrm{m} \mathrm{a}^{-1} \text { w.e. }\end{array}$} \\
\hline & & & & & & & \\
\hline Law Dome & $66.78^{\circ} \mathrm{S}, 112.82^{\circ} \mathrm{E}$ & 1370 & -19.4 & 1961-99 & $\delta^{18} \mathrm{O}$ & -22.3 & 0.67 \\
\hline Siple Station & $75.92^{\circ} \mathrm{S}, 84.15^{\circ} \mathrm{W}$ & 1054 & -25.0 & $1961-83$ & $\delta^{18} \mathrm{O}$ & -29.7 & 0.56 \\
\hline US ITASE 2001-5 & $77.06^{\circ} \mathrm{S}, 89.14^{\circ} \mathrm{W}$ & 1246 & -27.0 & 1961-2000 & $\delta^{18} \mathrm{O}$ & -31.5 & 0.38 \\
\hline US ITASE 2000-1 & $79.38^{\circ} \mathrm{S}, 111.23^{\circ} \mathrm{W}$ & 1791 & -31.1 & 1961-2000 & $\delta^{18} \mathrm{O}$ & -33.0 & 0.26 \\
\hline US ITASE 2000-5 & $77.68^{\circ} \mathrm{S}, 123.99^{\circ} \mathrm{W}$ & 1828 & -31.9 & 1961-2000 & $\delta \mathrm{D}$ & -264 & 0.12 \\
\hline Talos Dome & $72.37^{\circ} \mathrm{S}, 158.75^{\circ} \mathrm{E}$ & 2316 & -37.8 & $1961-96$ & $\delta \mathrm{D}$ & -292 & 0.09 \\
\hline
\end{tabular}


Instrumental climate observations are needed to facilitate the interpretation of proxy ice-core data, but long continuous meteorological records at ice-core sites in Antarctica are rare. Satellite-derived surface temperatures are now available (Comiso, 2000), providing an important data source for this purpose. Although satellite-derived temperatures are an imperfect estimate of the true surface temperature because of a clear-sky bias that is stronger in the winter, the correlation with ground-based observation on monthly to interannual timescales is very high (e.g. Shuman and Comiso, 2002; King and Comiso, 2003). For each location discussed below, we select the 18 year (1982-99) temperature time series $(T)$, at monthly resolution, from the approximately $50 \mathrm{~km} \times 50 \mathrm{~km}$ gridpoint in which the icecore site lies. The spatial resolution was reduced from the original satellite data by averaging adjacent pixel values. These data are limited in their temporal length, which poses problems for their use in interannual calibrations, but they are well suited for climatological $\delta-T$ correlations and the inference of spatial patterns of temperature variability (Kwok and Comiso, 2002; Schneider and others, 2004).

\section{RESULTS}

\section{Local correlations with temperature}

Various methods have been used to calibrate ice-core $\delta$ in terms of temperature variations. For example, Van Ommen and Morgan (1997) proposed that the seasonal variation in local temperature and isotope ratios could be applied to longer-term ice-core records that extend back into the last glacial period. Many other studies have instead applied modern spatial $\delta-T$ scaling to ice-core $\delta$ profiles (e.g. Petit and others, 1999). The seasonal temporal slope may be an improvement over the spatial slope. The latter has been shown to underestimate changes in temperature and to vary regionally (Jouzel and others, 1997), and there is no clear physical reason to link the spatial and temporal slopes (Bradley, 1999; Van Lipzig and others, 2002). Below, we adapt both methods for use with the satellite data before proceeding to, and comparing the results with, interannual $\delta-T$ correlations.

Records in Table 1 are listed in order of decreasing mean annual temperature. As shown here, the mean $\delta^{18} \mathrm{O}$ values are increasingly depleted following this ordering. On the basis of these data, a spatial slope of $0.9 \%{ }^{\circ} \mathrm{C}^{-1}$ for $\delta^{18} \mathrm{O}$ can be derived, consistent with $\delta-T$ slopes reported previously for Antarctica (e.g. Zwally and others, 1998). Shown in Figure 2 are the seasonal variations in $\delta^{18} \mathrm{O}$ and $T$ at four locations where sub-annual measurements are available. Each monthly value is an average of about 18 years of data

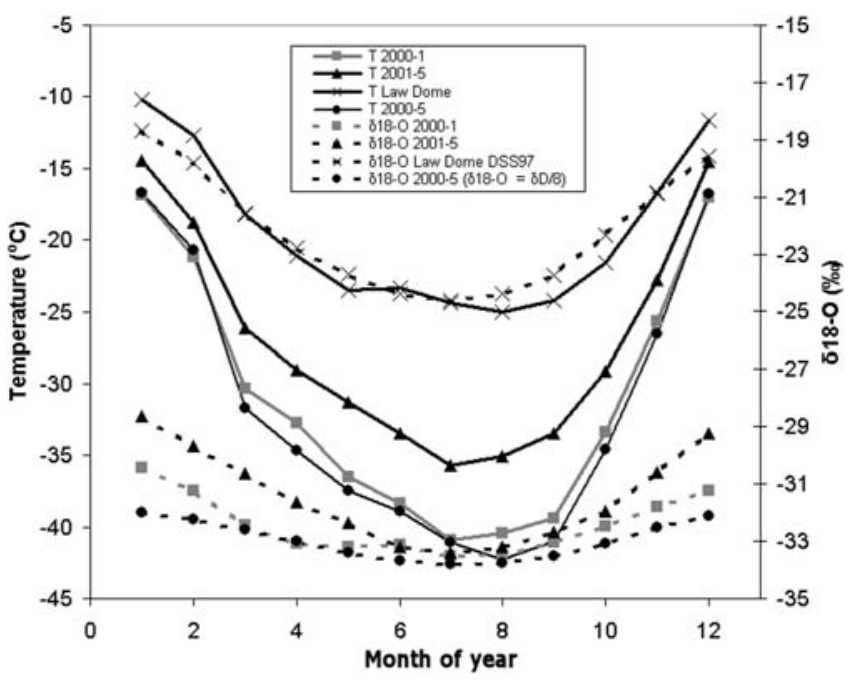

Fig. 2. Plot of 18 year monthly mean satellite-derived temperatures and corresponding isotopic values at various sites.

for that month. For comparison with the other cores, $\delta \mathrm{D}$ values from core 2000-5 have been scaled by a factor of $1 / 8$, to approximate $\delta^{18} \mathrm{O}$ variability. Table 2 summarizes the correlations between $T$ and $\delta$ and the equation of the linear best-fit line at each of these sites.

While all of the correlation coefficients are highly significant, the slopes vary and are all lower than the spatial slope. From Figure 2, it is apparent that the scaling of the $y$ axes, $0.50 \%{ }^{\circ} \mathrm{C}^{-1}$, approximates the actual relationship at Law Dome, while the other three sites have smaller slopes, which are given in Table 2. The temperature cycles are not sinusoidal but rather exhibit a broad winter minimum and short summer maximum, a well-known feature of Antarctic climatology (King and Turner, 1997). The isotopic cycles closely follow the shape of the temperature cycles, supporting a consistent $\delta-T$ relationship through the course of the year, but one that is specific to each site.

The difference in slopes among sites can at least in part be attributed to diffusion, which reduces the amplitude of the $\delta$ cycle at warmer and lower-accumulation-rate sites. We estimate the degree of diffusive loss, using an effective diffusion length calculated for local temperature and accumulation rate at each site, with the methods described in Cuffey and Steig (1998). The average amplitude loss can be estimated using the following equation from Johnsen and others (2000):

$$
I=100\left(1-\mathrm{e}^{-2(\pi L / \lambda)^{2}}\right)
$$

where $I$ is the relative (\%) amplitude of the seasonal cycle compared with the original amplitude, $L$ is the diffusion

Table 2. Mean monthly seasonal calibrations of $\delta$ with local $T$. If the correlation is significant, it is indicated in parentheses

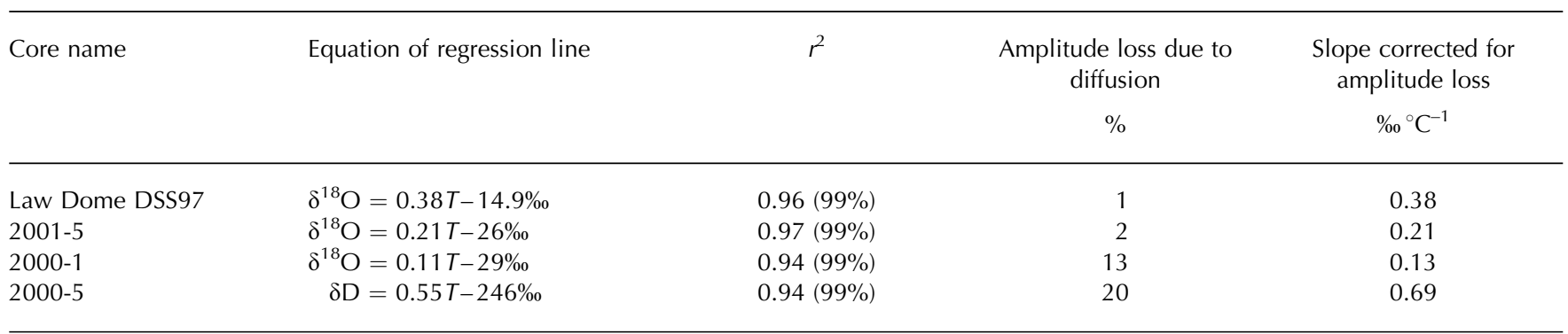


Table 3. Interannual calibrations of $\delta$ with local $T$

\begin{tabular}{lll} 
Core name & Equation of regression line & $r$ \\
\hline Law Dome 2000 & $\delta^{18} \mathrm{O}=0.44 T-14 \%$ o & 0.39 \\
Law Dome DSS97 & $\delta^{18} \mathrm{O}=0.49 T-13 \%$ o & 0.51 \\
$2001-5$ & $\delta^{18} \mathrm{O}=0.09 T-29 \%$ & 0.06 \\
$2000-1$ & $\delta^{18} \mathrm{O}=0.42 T-19 \%$ & 0.29 \\
$2000-5$ & $\delta \mathrm{D}=2.9 T-1.7 \%$ & 0.36 \\
Talos Dome & $\delta \mathrm{D}=3.43 T-159 \%$ & 0.25 \\
& & \\
\hline
\end{tabular}

length, and $\lambda$ is the annual-layer thickness. In Table 2, I has been estimated, and the corresponding $\delta-T$ slope has been compensated for this effect. As expected, the seasonal $\delta-T$ slopes are increased by a larger factor for the loweraccumulation-rate sites. Perhaps due to additional loss of the seasonal cycle amplitude by sublimation and redeposition of water vapor in the upper few $\mathrm{cm}$ of the firn (e.g. Neumann, 2003), which is not taken into account in this diffusion model, the corrected slope values still vary significantly among the ice cores.

To investigate interannual variability in $\delta$ and its relationship with $T$, annual mean values of $\delta$ based on the calendar year are calculated for each of the cores discussed above; annual data for Siple Station and Talos Dome were obtained from other investigators. Accumulation rates are high enough in the US-ITASE, Siple Station and Law Dome cores that seasonal variations are obvious, and the apparently limited diffusion should mean that accurate annual averages can be calculated, as the length over which diffusion acts is less than the thickness of an annual layer. At 2000-5, a relatively low-accumulation core, clear annual isotopic cycles are sometimes absent, though the calculated diffusion length is still less than the average annual accumulation rate. At Talos Dome, on the other hand, there are obvious $\delta \mathrm{D}$ cycles only in the upper $7-8 \mathrm{~m}$ of the firn, and the age control is less reliable (Stenni and others, 2002) than that of the other cores discussed here. Thus, this core may be less reliable than the others as an annually resolved record.

Interannual variations in $\delta$ have a much poorer fit with $T$ than do seasonal variations, and the $\delta-T$ correlation coefficients are quite low and not statistically significant (Table 3), perhaps due in part to the short length and high variance of the records. The $\delta-T$ slopes derived are not stable, as removing just a few outlying data points substantially alters the slope. For instance, in 2000-1, if just two data points are removed from the time series, the slope changes from $0.42 \%{ }^{\circ} \mathrm{C}^{-1}$ to $0.90 \%{ }^{\circ} \mathrm{C}^{-1}$. For the Law Dome cores, the calibration is somewhat more stable, but there is still a discrepancy (although smaller than that of the other cores) between the seasonal and interannual slopes. One reason may be that physical processes governing the seasonal variation of temperature (e.g. insolation) and the interannual variation of temperature (e.g. advection) are quite different. Thus, some researchers have suggested that isotopic fractionation should not be expected to respond in the same way to these processes (e.g. Cole and others, 1999).

\section{Correlations with large-scale and longer-term temperature indices}

Possibly, a stronger $\delta-T$ relationship could be found with accumulation-weighted annual values of $\delta$ and inversion-top
Table 4. Correlations of local variables ( $\delta$ and $T$ ) with a large-scale temperature index (A8). If the correlation is significant, it is indicated in parentheses

\begin{tabular}{llll}
\hline Site name & $\begin{array}{l}r, 1961-99 \mathrm{~A} 8 \\
\text { and } \delta\end{array}$ & $\begin{array}{l}r, 1982-99 \mathrm{~A} 8 \\
\text { and } \delta\end{array}$ & $\begin{array}{l}r, 1982-99 \mathrm{~A} 8 \\
\text { and } T\end{array}$ \\
\hline Siple Station & $0.68(95 \%)$ & & 0.00 \\
Law Dome 2000 & $0.42(95 \%)$ & $0.66(90 \%)$ & 0.47 \\
$2001-5$ & 0.19 & -0.13 & 0.26 \\
2000-1 & $0.33(90 \%)$ & 0.28 & 0.39 \\
2000-5 & $0.38(95 \%)$ & 0.44 & 0.21 \\
Talos Dome & -0.11 & -0.24 & 0.60 \\
\end{tabular}

temperatures (e.g. Van Lipzig and others, 2002), but that is beyond the limits of the available data. However, noise in individual records can be reduced through calculating averages or composites of ice cores and of the instrumental records with which they are compared.

An appropriate composite of instrumental data against which to evaluate all of the ice cores simultaneously should be one that is broadly representative of the study region. Although there are significant patterns of spatial variability in Antarctic climate, to first order temperature anomalies are remarkably coherent across the continent. A principal component analysis of satellite-derived temperatures covering the entire continent reveals that it is dominated by one mode, which has the same sign of anomaly nearly everywhere except for the north of the peninsula and explains $52 \%$ of the monthly variance and $62 \%$ of the variance in annually averaged data (Schneider and others, 2004). This mode would seem an ideal target against which to calibrate spatially dispersed ice cores. Unfortunately, the satellite data cover too short a period to provide a reliable interannual calibration; additionally, not all of our ice-core records overlap temporally with these data. Therefore, we use meteorological observations from staffed Antarctic research stations to derive a longer climate index that adequately describes the time variability of the leading spatial temperature pattern, while leaving higher-order and more complex spatial patterns for future studies.

The Reference Antarctic Data for Environmental Research (READER) project provides the most recent update of Antarctic station data (Turner and others, 2004), with data available online (www.antarctica.ac.uk/met/READER/). In this dataset, there are 14 stations with at least 30 years of monthly surface air-temperature data from the late 1950s to the present. Eight of these stations, which are indicated in Figure 1, have complete monthly records from 1961 to 1999, except for Scott Base, in which two months are missing in 1994 that we fill in with climatology. Principal component analysis applied to these stations results in a leading mode which explains $35 \%$ of the variance and has positive weights at each of the stations. The principal component associated with this mode is correlated with the simple mean of the constituent stations at $r=0.98$. The mean was formed by subtracting the 1961-90 monthly climatology from each station record before averaging all of the station anomalies. This composite index, denoted as A8, correlates with the mean and first principal component of the satellite data for 1982-99 at $r=0.72$ (significant at $95 \%)$, so it can be considered representative of the Antarctic 
Table 5. Ice-core records correlation matrix, 1961-99. If the correlation is significant, it is indicated in parentheses

\begin{tabular}{lllll}
\hline Core name & $\begin{array}{l}\text { Law Dome } \\
2000\end{array}$ & $2001-5$ & $2000-1$ & $2000-5$ \\
& & & & \\
\hline Law Dome 2000 & & -0.09 & 0.18 & 0.26 \\
$2001-5$ & -0.09 & & -0.01 & -0.10 \\
$2000-1$ & 0.18 & -0.01 & \multicolumn{2}{c}{$0.35(90 \%)$} \\
$2000-5$ & 0.26 & -0.10 & $0.35(90 \%)$ \\
\hline
\end{tabular}

as a whole. Further support for this idea is shown by the correlation of annual values of A8 with the gridded satellite data (Fig. 1). Nearly all areas have a positive correlation, except for the north of the peninsula. Over the whole continent, A8 explains $28 \%$ of the full spatial-temporal interannual variance in satellite-derived Antarctic temperatures. A8 is thus a useful benchmark for ice-core calibrations; it explains far more variance than other indices which are commonly invoked. For instance, the Southern Oscillation Index explains only $0.5 \%$ of the variance in Antarctic temperatures (Schneider and others, 2004).

Table 4 lists the correlations of $\delta$ and $T$ at each site with A8. Correlations for the short satellite period are compared with the full length of A8. For the period 1982-99, only Talos Dome $\delta$ has a significantly different correlation with local $T$ than with A8. Also, correlations of A8 and $\delta$ are consistent with the correlations of A8 and Tat the majority of the sites. For the longer period, most of the correlations of A8 and $\delta$ reach significance at the $90 \%$ level or above, but the magnitudes are not consistently greater than for the shorter period. Correlations among the four longest cores are mostly not significant (Table 5) despite the consistent and significant correlations with A8.

A composite index of annual ice-core time series is constructed by averaging all of the ice cores available during the overlap period with A8. The five cores included are those listed in Table 4, excluding Talos Dome because of its negative correlations. Because each $\delta$ series has a different mean and variance, the time series are normalized before computing the composite. The mean $\delta$ value over the 196190 overlapping reference period (1961-83 for Siple Station) is subtracted from the time series, and the result is divided by the standard deviation of the record during the same reference period. Over the period 1961-83, when all five cores are included, A8 and the composite are highly correlated ( $r=0.67$, significant at 95\%). For the full record, the correlation is $r=0.62$, significant at the $99 \%$ level. Also, the slight warming trend in $\mathrm{A} 8\left(+0.0024^{\circ} \mathrm{Ca}^{-1}\right)$ from 1961 to 1999 is closely tracked by an upward trend in the composite. In detail, this period is composed of a warming to 1981 , with a cooling tendency thereafter that is seen in both A8 and the ice-core composite (Fig. 3). These correlations are remarkable given the obvious disparity in the spatial sampling of the stations comprising A8 and the ice cores comprising the composite, and given the intrinsic uncertainties of the $\delta$ time series.

\section{Scaling relationships with Antarctic-wide temperature anomalies}

A straightforward way to express the ice-core composite in terms of the temperature variations measured in $A 8$ is

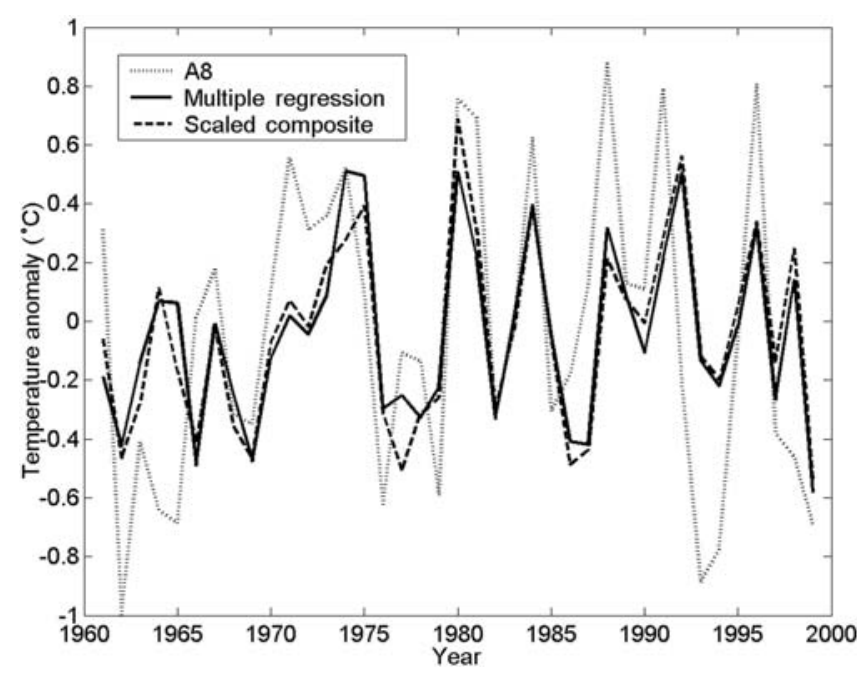

Fig. 3. Estimates of annually averaged Antarctic temperature anomalies from A8, a multiple linear regression model with ice cores as predictors and a scaled ice-core composite.

through a single regression. This may not result in an optimal or reliable estimate of temperature variability, because, as we have shown, there are differences in the sensitivity of the isotopic time series to temperature variations among the ice cores and across different timescales. Thus, multiple regression is also considered, since it can be objectively used to select which combination of ice cores best predicts the target time series, A8.

If the ice-core composite is simply scaled against A8, the regression coefficient in the equation, $A 8=0.52 *$ composite -0.08 , has a $95 \%$ uncertainty range of \pm 0.30 . A verification test, giving an indication of the stability of the regression, shows that regression coefficients for an early time period, 1961-80, and a late time period, 1981-99, are well within this $95 \%$ uncertainty band. The scaled composite time series does not change the correlation with A8 from the unscaled composite. The trend $\left(+0.0061^{\circ} \mathrm{Ca}^{-1}\right)$ and the variance $\left(0.10^{\circ} \mathrm{C}\right)$ of the scaled composite are overand underestimated, respectively, compared to the target A8 time series.

Correlations of individual cores with A8 (see Table 4) show that some $\delta$ records are better than others in tracking the climate index. Stepwise multiple linear regression, where at each step a $\delta$ record is added to the predictors in order of decreasing correlation with the predictand (Table 6), ultimately leads to results similar to those of the simple composite. With the four long ice-core records and a 196199 calibration period, the coefficients used to predict A8 are those in the bottom row of Table 6 . The predicted time series (A8proxy) is highly correlated with A8 ( $r=0.59$, significant at 99\%; Fig. 3). The 1961-99 trend in A8proxy $\left(+0.0037^{\circ} \mathrm{Ca}^{-1}\right)$ is very close to the trend in A8 itself. The variance in the reconstruction $\left(0.09^{\circ} \mathrm{C}\right)$ is underestimated compared to the variance in the station time series $\left(0.27^{\circ} \mathrm{C}\right)$.

A simple but strict cross-validation exercise is performed to test the ability of the predictors to predict time periods independent of the multiple regression. The data are split into an early and a late period, 1961-80 and 1981-99. Coefficients from the early-period fitting are used to predict the late period and vice versa. Values of $r^{2}$ for the crossvalidation are presented in Table 6. The somewhat low 
Table 6. Stepwise multiple linear regression models. Coefficients, read across in each row, are those applied to the respective ice-core time series to predict A8. $R^{2}$ values indicate how much variance is explained in A8 by the prediction at each step, with the significance level shown in parentheses. At right, in italics: cross-verification exercise in which the prediction is verified in a time period independent of the calibration

$\begin{array}{lllllll}\text { Law Dome } 2000 & 2000-5 & 2000-1 & 2001-5 & 1961-99 \text { calibration, } & 1961-80 \text { calibration; } & 1981-99 \text { calibration; } \\ \text { coefficients } & \text { coefficients } & \text { coefficients } & \text { coefficients } & \text { no verification }\left(r^{2}\right) & \begin{array}{l}1981-99 \text { verification } \\ \left(r^{2}\right)\end{array} & \end{array}$

\begin{tabular}{|c|c|c|c|c|c|c|c|}
\hline Step 1 & 0.22 & & & & $0.18(95 \%)$ & 0.44 & 0.02 \\
\hline Step 2 & 0.15 & 0.18 & & & $0.26(95 \%)$ & 0.24 & 0.05 \\
\hline Step 3 & 0.09 & 0.11 & 0.17 & & $0.29(99 \%)$ & 0.22 & 0.05 \\
\hline Final model & 0.18 & 0.13 & 0.08 & 0.13 & $0.35(99 \%)$ & 0.07 & 0.11 \\
\hline
\end{tabular}

values are indicative of the problem of a limited dataset and of extreme year-to-year variability in the target index, A8. Given the short time periods involved, single years can significantly change the cross-validation $r^{2}$ value. Since we do not have the luxury of a long cross-validation dataset, we also use a less strict test that is often applied to short datasets (e.g. Wilks, 1995). This involves removing one year at a time, predicting the missing year, and compositing the single-year predictions into a verification time series, as was recently applied to tree rings by Jones and Widmann (2003). With this verification scheme, A8 and the verification time series are correlated at $r=0.45$, significant at $95 \%$, indicative of the overall stability of the reconstruction, but again a reflection of the fact that not all individual years are correctly predicted, as can clearly be seen in Figure 3 .

Reconstructions using the multiple linear regression and composite methods are correlated with each other at $r=0.95$ (significant at 99\%) and have a similar magnitude of correlation with A8. Thus, although the seasonal sitespecific $\delta-T$ slopes vary, the similarity of the multiple linear regression results and composite results suggests that it is appropriate, in this case, to weight the normalized isotopic records equally.

\section{DISCUSSION}

The results presented above show a strong relationship between monthly estimates of $\delta$ and Tover the course of the seasonal cycle. However, on an interannual timescale, to the extent that they can be consistently defined, linear transfer functions are of little value when the correlation coefficient of $\delta$ with $T$ is low. This finding of low interannual $\delta-T$ correlation is consistent with that of isotopic modelling studies (Cole and others, 1999; Noone and Simmonds, 2002b; Werner and Heimann 2002).

Compared with local $T$, a large-scale climate index, A8, does not substantially improve the amount of variance that can be explained in a single record of $\delta$ over the same time period. Over the 39 year time period, the magnitude of variance explained in $\delta$ by A8 is not systematically increased, but the statistical significance of the correlation is improved (Table 4). While the ice cores have only a modest correlation with site temperature and with A8 during 1961-99, they are not all correlated with each other (Table 5), but they are consistently correlated with A8 (except for Talos Dome), so they are not redundant predictors. This attests to the large-scale representativeness of A8 and the physical processes it reflects. It implies not only temperature changes over a broad area of the ice sheet (see Fig. 1), but also circulation changes (Schneider and others, 2004), which in turn alter precipitation timing, winds, moisture origin and transport pathways, and condensation histories. These are the same factors which a number of studies have shown influence interannual variations in $\delta$ (Cole and others, 1999; Noone and Simmonds 2002a, b; Van Lipzig and others, 2002; Werner and Heimann, 2002), and which are, as Noone and Simmonds (2002a) discuss, systematically altered by the SAM. A composite of five normalized $\delta$ profiles explains a substantial amount of variance (roughly $45 \%$ ) in A8. Through multivariate techniques or by simply scaling the composite, the ice-core reconstruction can be expressed in terms of temperature variations, with the two methods yielding very similar results. White and others (1997) used a similar method of computing an ice-core composite for central Greenland and explained a comparable amount of variance through a multiple linear regression. However, that regression relied upon a number of climate indices which were not all independent of each other, whereas we have only used one primary index, A8. When using just one climate index, Greenland temperatures, White and others (1997) found a lower correlation than we have: $r=0.47$ with their ice-core composite.

The SAM is the prominent feature in mid- to high-latitude tropospheric atmospheric circulation (Thompson and Wallace, 2000). Because the SAM is a roughly zonally symmetric oscillation, it affects temperature anomalies at Antarctic stations and in the continental interior apart from the peninsula region in the same sense (Thompson and Wallace 2000; Schneider and others, 2004). Regression of its index against satellite-derived surface temperatures explains about $18 \%$ of the variance on both monthly and interannual timescales (Schneider and others, 2004). Similarly, A8 is significantly correlated (at 99\%) with the 196998 SAM index of Thompson and Solomon (2002), which is based on radiosonde measurements of $500 \mathrm{hPA}$ geopotential heights, at $r=-0.78$. As noted above, Noone and Simmonds (2002a, b) show that Antarctic isotope variability is also strongly controlled by the SAM. However, due to the high covariance between A8 and the SAM index, it is somewhat arbitrary whether variability in the ice-core composite is attributed to the SAM, to temperature, or to a combination of the two. On the other hand, it is notable that, without any fitting, the ice-core composite more closely tracks the variations and trends in $\mathrm{A} 8$ than in the SAM ( $r$ (composite, SAM index 1969-98) $=-0.33$ ). Thus, 
the ice-core composite cannot be simply viewed as a surrogate for the SAM index, though if viewed as a temperature index, it clearly has a relationship with the SAM consistent with that from modern instrumental observations.

\section{CONCLUSIONS}

In the ice-core records we have examined, site-specific $\delta-T$ correlations are strong on a seasonal basis, and reinforce use of stable isotopes as temperature proxies. On the other hand, differences among seasonal slopes cannot be fully explained in terms of simple diffusion models, though more complete models may provide an improved assessment of the slope differences. Furthermore, differences between seasonal slopes and interannual slopes probably arise from different physical processes acting on both the variation of site temperature and the history of air masses en route to the deposition site. At the interannual scale, a regional temperature index (A8) explains at least as much variance in local $\delta$ records as the site temperature, and embodies many of the relevant physical processes, as shown by its covariance with temperatures across the continent and with the SAM.

We suggest that the statistical reconstruction methods described here, with a focus on larger-scale processes as opposed to site-specific phenomena, are a viable approach towards reconstruction of interannual climate variability from ice cores. Our results demonstrate that meaningful estimates of the interannual variability and trends in 40 years of Antarctic temperature anomalies can be made with either a multiple linear regression model or a scaled composite on the basis of several well-dated, high-resolution ice-core records. Each additional record, with the exception of Talos Dome, improves the variance explained in temperature; thus we anticipate that additional high-resolution, well-dated ice-core records will further improve the statistical skill of the calibration. As more data are added, however, records which clearly do not hold a significant physical relationship with the target index (e.g. Talos Dome) should be avoided. Verification exercises can be used to determine the reliability of such models. These calibration results are important because they suggest that the primary signal of temperature variability in the Antarctic may be reconstructed from $\delta$ records. Moreover, they are not simply fortuitous, as physical models independently show the strong linkages among $\delta$ records, temperatures and the SAM (Noone and Simmonds, 2002a,b). These results suggest promise for meeting one of the major goals of ITASE: quantitatively reconstructing the last $\sim 200$ years of climate variability in the Antarctic.

\section{ACKNOWLEDGEMENTS}

The entire US-ITASE field team led by P. Mayewski made this study possible. We thank J. Flaherty and the University of Washington Stable Isotope Laboratory for isotopic measurements on the US-ITASE cores. E. Mosley-Thompson kindly provided ice-core data from Siple Station, while Talos Dome data were available online at the National Snow and Ice Data Center, Boulder, CO, USA. We thank J. Comiso and C. Shuman of NASA for providing the satellite data. J. Wettstein made valuable comments on the initial manuscript. Three reviewers provided additional comments which improved the paper. D. Schneider and E. Steig are supported by the US National Science Foundation, Office of Polar Programs, grant OPP-0196105. T. van Ommen is supported by the Australian Government's Cooperative Research Centre Program through the Antarctic Climate and Ecosystems CRC.

\section{REFERENCES}

Bradley, R.S. 1999. Paleoclimatology: reconstructing climates of the Quaternary. San Diego, CA, Academic Press.

Bretherton, C.S., M. Widmann, V. Dymnikov, J.M. Wallace and I. Blade. 1999. The effective number of spatial degrees of freedom in a time-varying field. J. Climate, 12, 1990-2009.

Cole, J.E., D. Rind, R.S. Webb, J. Jouzel and R. Healy. 1999. Climatic controls on $\delta^{18} \mathrm{O}$ variability of precipitation: simulated influence of temperature, precipitation amount, and vapor source region. J. Geophys. Res., 104(D12), 14,223-14,235.

Comiso, J.C. 2000. Variability and trends in Antarctic surface temperatures from in situ and satellite infrared measurements. J. Climate, 13(10), 1674-1696.

Cuffey, K.M. and E.J. Steig. 1998. Isotopic diffusion in polar firn: implications for interpretation of seasonal climate parameters in ice-core records, with emphasis on central Greenland. J. Glaciol., 44(147), 273-284.

Dansgaard, W. 1964. Stable isotopes in precipitation. Tellus, 16(4), 436-468.

Dixon, D., P.A. Mayewski, S. Kaspari, S. Sneed and M. Handley. 2004. A 200-year sub-annual record of sulfate in West Antarctica from 16 ice cores. Ann. Glaciol., 39, 545-556.

Houghton, J.T. and 7 others. 2001. Climate change 2001: the scientific basis. Cambridge, etc., Cambridge University Press.

Johnsen, S.J., H.B. Clausen, K.M. Cuffey, G. Hoffmann, J. Schwander and T. Creyts. 2000. Diffusion of stable isotopes in polar firn and ice: the isotope effect in firn diffusion. In Hondoh, T., ed. Physics of ice core records. Sapporo, Hokkaido University Press, 121-140.

Jones, J.M. and M. Widmann. 2003. Instrument- and tree-ringbased estimates of the Antarctic oscillation. J. Climate, 16(21), 3511-3524.

Jouzel, J. and 12 others. 1997. Validity of the temperature reconstruction from water isotopes in ice cores. J. Geophys. Res., 102(C12), 26,471-26,487.

Karl, T.R. and K.E. Trenberth. 2003. Modern global climate change. Science, 302(5651), 1719-1723.

King, J.C. and J.C. Comiso. 2003. The spatial coherence of interannual temperature variations in the Antarctic Peninsula. Geophys. Res. Lett., 30(2), 1040. (10.1029/2002GL015580.)

King, J.C. and J. Turner. 1997. Antarctic meteorology and climatology. Cambridge, etc., Cambridge University Press.

Kwok, R. and J.C. Comiso. 2002. Spatial patterns of variability in Antarctic surface temperature: connections to the Southern Hemisphere annual mode and the Southern Oscillation. Geophys. Res. Lett., 29(14), 1705. (10.1029/2002GL015415.)

Masson-Delmotte, V. and 6 others. 2003. Recent southern Indian Ocean climate variability inferred from a Law Dome ice core. Climate Dyn., 21(2), 153-166.

Mayewski, P.A. and 10 others. 2004. A 700 year record of Southern Hemisphere extratropical climate variability. Ann. Glaciol., 39, 127-132.

Mosley-Thompson, E., L.G. Thompson, P.M. Grootes and N. Gundestrup. 1990. Little Ice Age (neoglacial) paleoenvironmental conditions at Siple Station, Antarctica. Ann. Glaciol., 14, 199-204.

Neumann, T.A. 2003. Effects of firn ventilation on geochemistry of polar snow. (PhD thesis, University of Washington.)

Noone, D. and I. Simmonds. 2002a. Annular variations in moisture transport mechanisms and the abundance of $\delta^{18} \mathrm{O}$ in Antarctic snow. J. Geophys. Res., 107(D24), 4742. (10.1029/2002JD002262.) 
Noone, D. and I. Simmonds. 2002b. Associations between $\delta^{18} \mathrm{O}$ of water and climate parameters in a simulation of atmospheric circulation for 1979-95. J. Climate, 15(22), 3150-3169.

Palmer, A.S., T.D. van Ommen, M.A.J. Curran and V. Morgan. 2001. Ice-core evidence for a small solar source of atmospheric nitrate. Geophys. Res. Lett., 28(10), 1953-1956.

Petit, J.R. and 18 others. 1999. Climate and atmospheric history of the past 420,000 years from the Vostok ice core, Antarctica. Nature, 399(6735), 429-436.

Schneider, D.P., E.J. Steig and J.C. Comiso. 2004. Recent climate variability in Antarctica from satellite-derived temperature data. J. Climate, 17(7), 1569-1583.

Shuman, C.A. and J.C. Comiso. 2002. In situ and satellite surface temperature records in Antarctica. Ann. Glaciol., 34, 113-120.

Steig, E.J. and 16 others. 2005. High-resolution ice cores from US ITASE (West Antarctica): development and validation of chronologies and determination of precision and accuracy. Ann. Glaciol., 41 (see paper in this volume).

Stenni, B. and 6 others. 2002. Eight centuries of volcanic signal and climate change at Talos Dome (East Antarctica). J. Geophys. Res., 107(D9), 4076. (10.129/2000JD000317.)

Thompson, D.W.J. and S. Solomon. 2002. Interpretation of recent Southern Hemisphere climate change. Science, 296(5569), 895-899.

Thompson, D.W.J. and J.M. Wallace. 2000. Annular modes in the extratropical circulation. Part I: Month-to-month variability. J. Climate, 13(5), 1000-1016.
Turner, J. and 8 others. 2004. The SCAR READER project: toward a high-quality database of mean Antarctic meteorological observations. J. Climate, 17(14), 2890-2898.

Van Lipzig, N.P.M., E. van Meijgaard and J. Oerlemans. 2002. The effect of temporal variations in the surface mass balance and temperature-inversion strength on the interpretation of ice-core signals. J. Glaciol., 48(163), 611-621.

Van Ommen, T.D. and V. Morgan. 1997. Calibrating the ice core paleothermometer using seasonality. J. Geophys. Res., 102(D8), 9351-9357.

Van Ommen, T.D., V. Morgan and M.A.J. Curran. 2004. Deglacial and Holocene changes in accumulation at Law Dome. Ann. Glaciol., 39, 359-365.

Vaughan, D.G. and 8 others. 2003. Recent rapid regional climate warming on the Antarctic Peninsula. Climatic Change, 60(3), 243-274.

Werner, M. and M. Heimann. 2002. Modeling interannual variability of water isotopes in Greenland and Antarctica. J. Geophys. Res., 107(D1), 4001. (10.1029/2001JD900253.)

White, J.W.C. and 7 others. 1997. The climate signal in the stable isotopes of snow from Summit, Greenland: results of comparisons with modern climate observations. J. Geophys. Res., 102(C12), 26,425-26,439.

Wilks, D.S. 1995. Statistical methods in the atmospheric sciences, 59. San Diego, CA, Academic Press.

Zwally, H.J., M. Giovinetto, M. Craven, V. Morgan and I. Goodwin. 1998. Areal distribution of the oxygen-isotope ratio in Antarctica: comparison of results based on field and remotely sensed data. Ann. Glaciol., 27, 583-590. 